American Journal of Agricultural and Biological Sciences 4 (1): 39-48, 2009

ISSN 1557-4989

(C) 2009 Science Publications

\title{
The Land Uses' Consequences in Coastal Area of Faliraki and Delta Penaeus River in Greece
}

\author{
Agisilaos Economou \\ National Technical University of Athens, Nikaias 18, 17122, Athens, Greece
}

\begin{abstract}
Problem statement: The areas of Faliraki and Delta Pinaeus river is presented with downgrade in natural resources that has a direct affect on the future development of these areas. This research investigated (i) whether land uses have downgraded the coastal areas (ii) to which degree the determination of land uses can play an important role in the reduction of environmental problems and in the protection of an area. Approach: An exploratory descriptive statistics and a comparative method were used on the employment in the productive sectors, built-up development and tourist development. In addition to this, personal interviews took place with the people in charge of technical services of corresponding municipalities. Moreover, the study was focused not only on the factors that cause the territorial changes, their way of connection with the environmental problems and the degradation of natural resources but also on the connection of conflicts of land uses with application problems in landplanning policy and on their effort of confronting these problems. Results: The areas were presented with similar activities in various sectors and many differences in the intensity of land uses. Faliraki had a powerful tertiary sector in contrast to Delta Pinaeus' area that had a powerful primary sector. The building activity in Faliraki was pointed out, which coincided with a big tourist development. On the other hand in Delta Pinaeus' area there was building activity only in area of Aiganis. Faliraki presented a high hotel potential and a big tourist movement whereas the Delta Pinaeus' area is characterized by a low hotel potential and a small tourist movement. Conclusion: The research showed that the intensities of land uses cause the main environmental problems in the coastal area. The attendance of local Authorities and citizens plays an important role to the development and the protection of the environment. For the reduction of environmental repercussions not only the regulation of land uses by the state but also their application by the residents is required.
\end{abstract}

Key words: Coastal, integrated coastal zone management, ICZM

\section{INTRODUCTION}

The last decades the coastal area many pressures are taken on the man-made activities. Mentionable natural resources in combination with various policies that are followed tourism development in the vocational period in the coastal area. This development led to a further built-up development that was contrary to not only to the natural environment. Thus, in many coastal agricultural and semi-urban areas, all the above land uses conflicts are frequent in Greece ${ }^{[1]}$.

For the examination of all the above consequences, the research is focused on tow case studies. That happened because it was impossible to study the Greek coastal area in total due to his huge size. Thus, the choice of two areas resulted from the typology of the coastal area taking as criteria the activities' tourisms in order to consist representative samples for many areas of the Greek coastal area.
The study is structured as follows. Initially, two cases studies are presented and their main characteristics are recorded. Then, the two areas are compared regarding to their employment, to their intensity of land uses and to their tourist development. Then, the environmental problems of two areas are presented, the problems of land uses' determination and the various policies that have affected the configuration of current land uses. Finally, the directions of landplanning drawings of land uses are presented for further development and conclusions.

As it will be proved, the case studies present many present many similarities in the human activities. However, they differ to their size and to their intention and that results to different level of consequences. The resulting problems are much greater when the development exceeds the carrying capacity of the areas. That results to the degradation of the natural resources as well as of the area in general. 


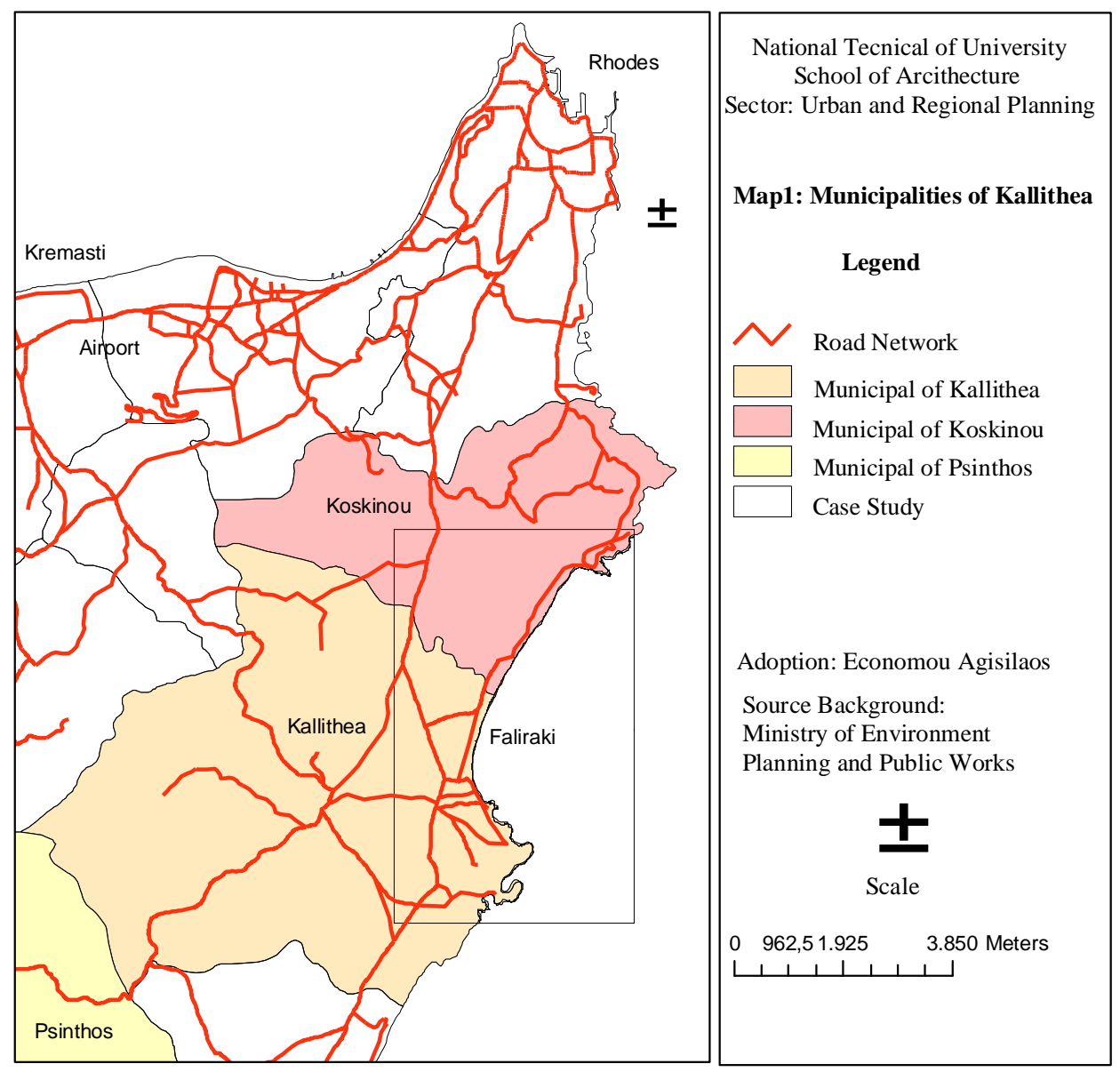

Fig. 1: Municipalities boroughts in area of Faliraki

Case studies: The coastal area of Faliraki of Rhodes island: Geographically, the coastal area of Faliraki belongs in the region of Southern Aegean and concretely in the Municipality of Kallithea of Island Rhodes (Fig. 1). Initially, the area was rural, up to the beginning of decade of ' 70 . The appreciable natural resources encouraged the tourist development, which showed important increase during the decade of ' 80 that is continued until today with smaller rate in the last year ${ }^{[2]}$.

Thus, today the area is characterized by the big hotels units that are found at northern part of Faliraki and the small one that are scattered in all his extent (Fig. 2). The area is characterized by the big duration of tourist period (March-November) and the quality of tourists (mainly tourists of western type) and the circuit of tour operator.

The result of this tourist development, apart from the hotels units, it was the creation of small settlement residents, which includes various enterprises of tourist interest. The area accepts direct influence from the city of Rhodes that show big tourist movement.

The coastal area of Delta Penaeus river: Geographically, the coastal area of Delta Penaeus belongs in the regions of Thessaly and administratively belongs in two Municipalities (Municipality of Evrymenon and Municipality of Down Olympus). The area of Delta Penaeus river includes a extensive plain between the mountain ranges of Down Olympus and Ossas. The coastal area of Delta includes the settlements, Omolio, Palaiopyrgo, Mesangal, Strintzo, Kouloura and Stomio (Fig. 3).

Initially, in the region big forestal extents existed, where big part of these extents were changed in rural land. After the decade of 30 due to his policy that was applied by the Agriculture Ministry for increase of rural land. Up to 1940, the land-planning structure in local level was distinguished by the social and the plain of Delta Penaeus. After the war, with the abandonment of 
mountainous regions, the economic interest is focused on the agricultural exploitation of plain of Delta Penaeus ${ }^{[3]}$.

The economic interest of areas was focused mainly on the coastal area of Delta due to the application of tourist political afterwards 1970 and the fact that the neighbouring big city Larissa had begun to transformed into Metropolitan centre having only one marine exit Platamonas and Delta of Penaeus. This occurred because the coastal Platamonas had almost reached saturation point. Progressively, the area comes out from the isolation and begins to be developed tourist, so it becomes area of seasonal residence and tourist exploitation. Today the tourist areas are the coastal settlements of Aeganis and Stomio where they present small hotels units and small tourist period (JuneSeptember) (Fig. 4) ${ }^{[3]}$.

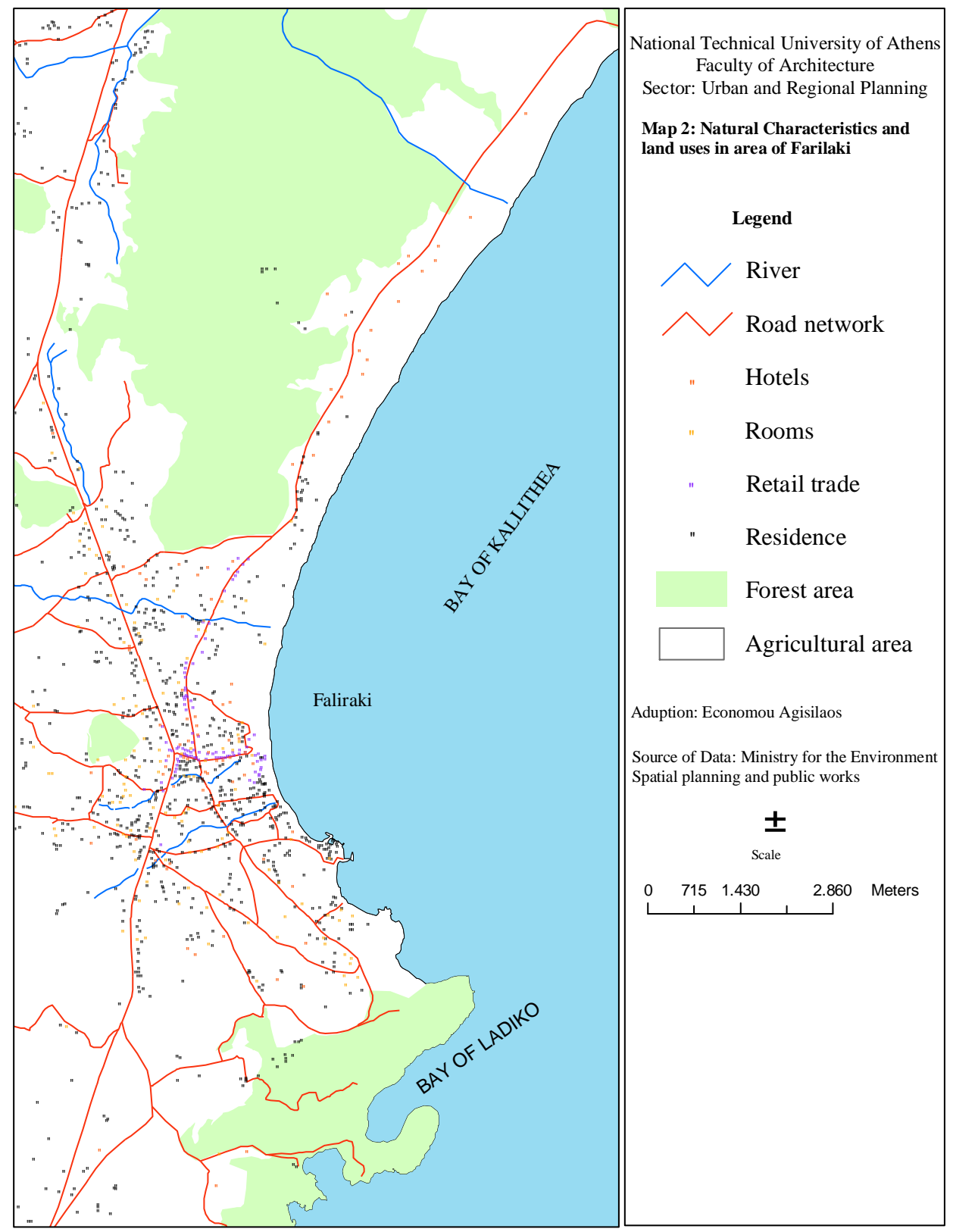

Fig. 2: Geophysical map of faliraki 

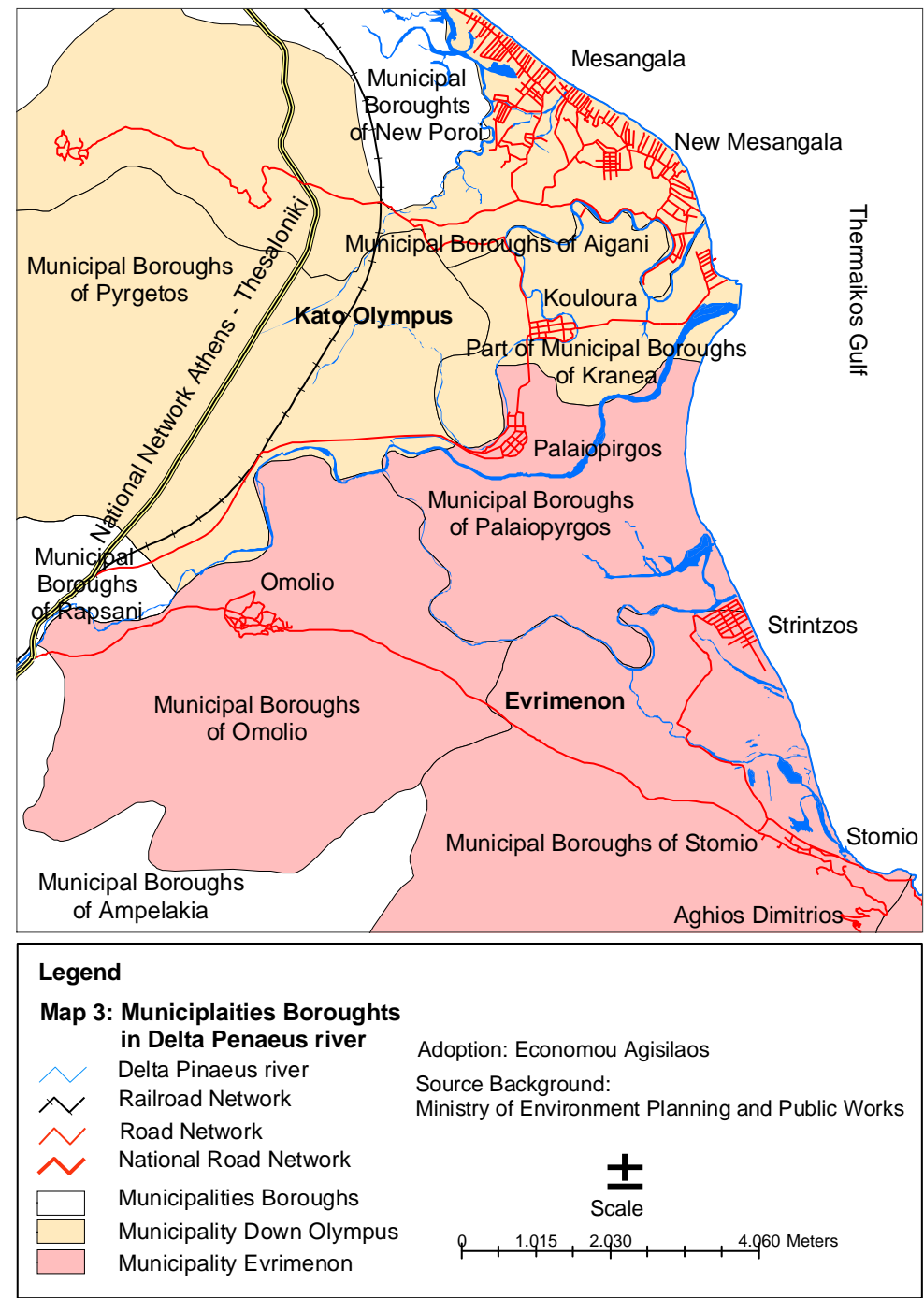

Fig. 3: Municipalities boroughts in Delta Penaeus

\section{MATERIALS AND METHODS}

In the present research the exploratory descriptive statistics on the employment in the productive sectors (period time 1980-2001), the built-up development (period time 1920-2000), the tourist development (period time 1970-2004) and the tourist movement in the period time 1993-2004 was used. Then a comparative method was applied in order to interpret the various phenomena of the intensity of land uses and to locate their causes.

The creation of maps took place with the use of Geographic Information Systems (GIS), Sources of cartographic data constituted orthophotomaps, aerial photographs, topographic diagrams and data that was collected by on the spot research and observation. Also other data such as, statistical data, land-planning drawings and studies of corresponding areas was used. In addition to this, personal interviews took place with the people in charge of technical services of corresponding municipalities.

The research was focused not only on the factors that cause the territorial changes (conflicts, intensities and land uses' changes) and on their way of connection with the environmental problems and the degradation of natural resources but also, it focused on the connection of conflicts of land uses with the application's problems of land-planning policy and on their effort of confrontation. Moreover, the forecasts of land-planning drawings of corresponding regions for the development and the protection of areas were mentioned. 

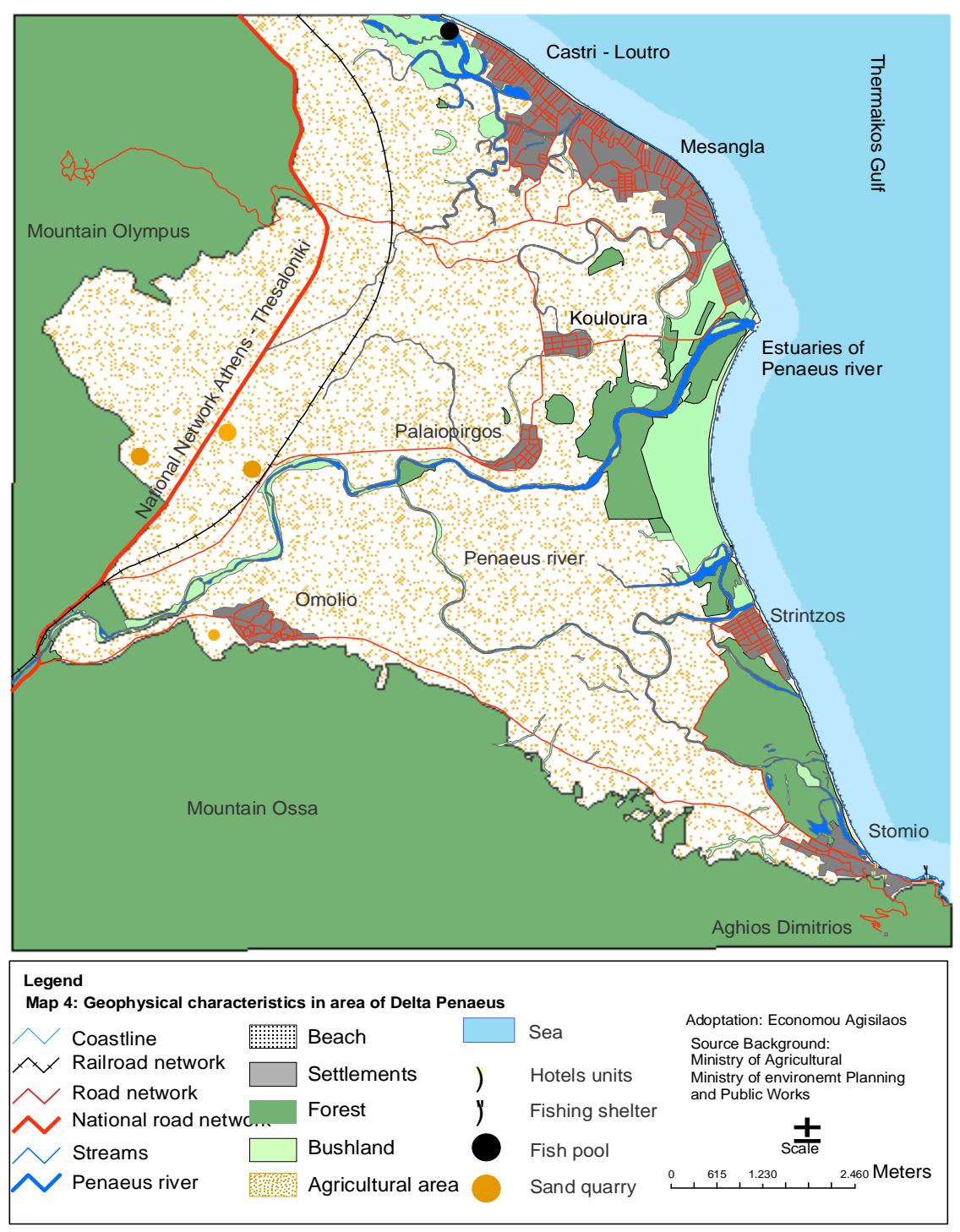

Fig. 4: Geophysical map in area of Delta Penaeus

\section{RESULTS}

With regard to the development of production's sector, the areas presented important differences. The Faliraki presents powerful tertiary sector (Table 1) in contrast to the Delta that presents a differentiation. The primary sector predominates in the area of Stomio, Omolio, Kranea and Palaiopyrgo in contrast to the area of Aiganis where the secondary sector predominates (Table 2).

The decade of ' 80 and afterwards, it is realised that in the area of Faliraki the big building activity is pointed out, which coincides with the big tourist development of area (Fig. 5.)
Table 1: Sectors of productivities in area of Kallithea-Faliraki ${ }^{[4]}$

\begin{tabular}{lcc}
\hline Year & $1991(\%)$ & $2001(\%)$ \\
\hline Sector of production & & \\
Primary sector $(\%)$ & 54.00 & 58.00 \\
& 4.27 & 2.54 \\
Secondary sector $(\%)$ & 228.00 & 376.00 \\
& 18.02 & 16.50 \\
Tertiary sector (\%) & 885.00 & 1546.00 \\
& 69.96 & 67.84 \\
New and not declared $(\%)$ & 98.00 & 299.00 \\
& 7.75 & 13.12 \\
\hline Total & $1265.00(100)$ & $2279.00(100)$ \\
\hline
\end{tabular}

On the contrary, in the area of Delta Penaeus the big building activity is presented in the area of Aiganis with a peak the decade of 90 (Fig. 6). 
Am. J. Agri. \& Biol. Sci., 4 (1): 39-48, 2009

Table 2: Sectors of productivities in the are of Delta Penaeus river ${ }^{[4]}$

\begin{tabular}{|c|c|c|c|c|c|c|c|c|c|c|}
\hline \multirow{3}{*}{$\begin{array}{l}\text { Sector of production } \\
\text { Year }\end{array}$} & \multicolumn{8}{|c|}{ Municipalities boroughts } & & \\
\hline & \multicolumn{2}{|c|}{ Kranea } & \multicolumn{2}{|c|}{ Aigani } & \multicolumn{2}{|c|}{ Palaiopyrgos } & \multicolumn{2}{|c|}{ Omolio } & \multicolumn{2}{|c|}{ Stomio } \\
\hline & 1991 & 2001 & 1991 & 2001 & 1991 & 2001 & 1991 & 2001 & 1991 & 2001 \\
\hline Primary sector & 42.00 & 43.00 & 189.00 & 117.00 & 54.00 & 55.00 & 126.00 & 132.00 & 82.00 & 110.00 \\
\hline (\%) & 29.17 & 31.16 & 53.09 & 29.47 & 48.65 & 32.93 & 37.95 & 48.53 & 35.97 & 41.20 \\
\hline Secondary sector & 21.00 & 24.00 & 83.00 & 135.00 & 16.00 & 48.00 & 108.00 & 47.00 & 40.00 & 48.00 \\
\hline (\%) & 14.58 & 17.39 & 23.32 & 34.01 & 14.41 & 28.74 & 32.53 & 17.28 & 17.54 & 17.98 \\
\hline Tertiary sector & 44.00 & 57.00 & 70.00 & 122.00 & 30.00 & 53.00 & 74.00 & 81.00 & 79.00 & 83.00 \\
\hline$(\%)$ & 30.56 & 41.30 & 19.66 & 30.73 & 27.03 & 31.74 & 22.29 & 29.78 & 34.65 & 31.08 \\
\hline New and not declared & 37.00 & 14.00 & 14.00 & 23.00 & 11.00 & 11.00 & 24.00 & 12.00 & 27.00 & 26.00 \\
\hline$(\%)$ & 25.69 & 10.15 & 3.93 & 5.79 & 9.91 & 6.59 & 7.23 & 4.41 & 11.84 & 9.74 \\
\hline Total & 144.00 & 138.00 & 356.00 & 397.00 & 111.00 & 167.00 & 332.00 & 272.00 & 228.00 & 267.00 \\
\hline
\end{tabular}

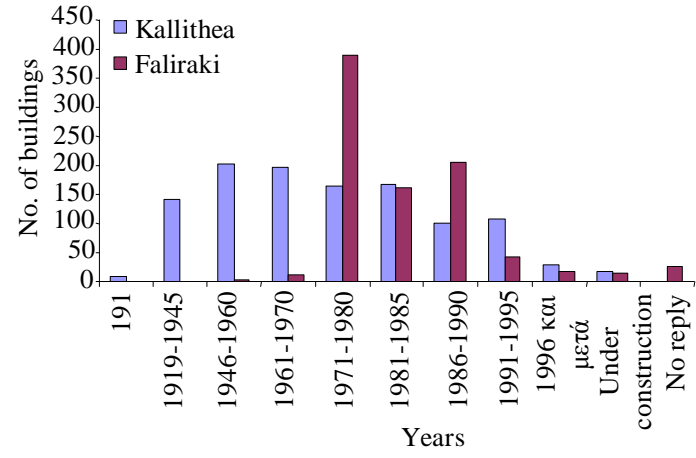

Fig. 5: Construction in area of bearaught Municipality of Kallithea during the period time $1920-2000^{[5]}$

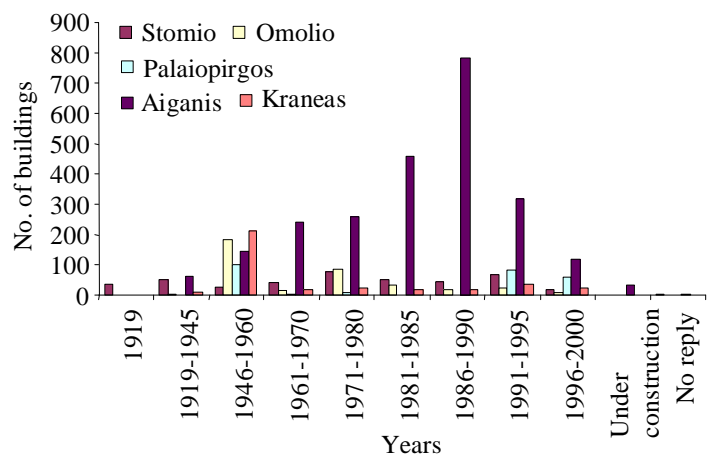

Fig. 6: Construction in area of delta penaeus during the period time $1920-2000^{[5]}$

Taking into consideration the tourist movement of both areas during the last decades, it is observed that the area of Faliraki belongs in the categories of coastal areas with a high hotel potential (Table 3), a high number of arrivals (Fig. 7) and a high number of overnight stays, fact that classifies the area in the bigger tourist resorts of country. On the contrary, the area of Delta Penaeus belongs to them with a low hotels potential (Table 3), a low number of arrivals (Fig. 8) and overnight stays, a high degree of natural resources due to the Delta Penaeus and appreciable ecosystems.
Table 3: Potential hotel ${ }^{[7]}$

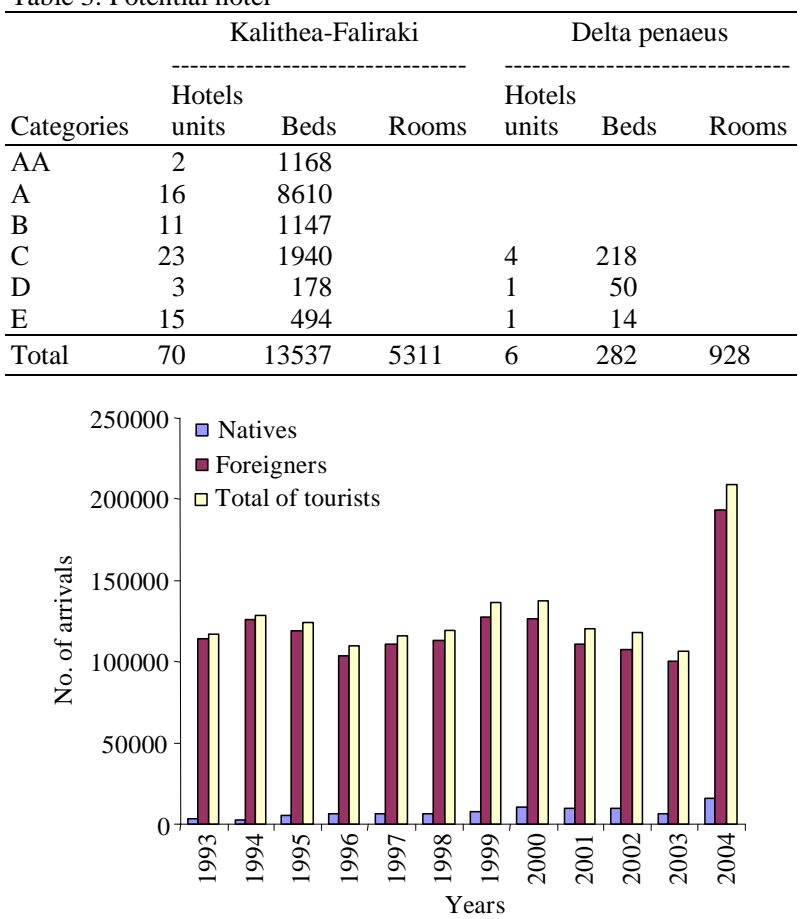

Fig. 7: Tourist movement in Faliraki of Kallithea during the period time 1993-2004 ${ }^{[6]}$

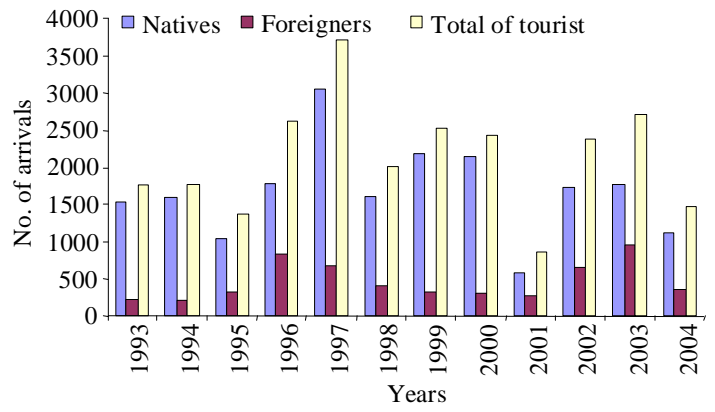

Fig. 8: Tourist movement in Stomio during the period time $1993-2004^{[6]}$ 


\section{DISCUSSION}

Intensity of human activities: Comparing the both case studies between them, it was realised that while they are exist the same activities in the various sectors (with the exception of the quarries and the piscicultures), these are differed as to their size and to their intensity.

The area of Faliraki presents bigger intensity of land uses with regard to the tourist sector, due to the big tourist development, in contrary to the area of Delta Penaeus that presents bigger intensity of land uses in the agriculture sector.

Both regions differ to their intensity on the agricultural and tourist sector. This does not happen on the constructional sector, where it has presented big building activity. The Faliraki with the development of big hotels units and rented rooms and the on the other hand Delta Penaeus with the development of mainly seasonal residence and rented rooms mainly in the area of Aiganis.

Today, in both areas a decrease of building activity, is observed due to the fact that they have been built to a large extent.

With regard to the other human activities, as in the Faliraki but also in the Delta Penaeus, they are of smaller intensity and they can influence the area in a smaller degree.

Tourism development: With regard to the tourist movement, the regions presented many differences to their size, to their duration of stays, to the length of tourist period, to their origin and to their quality of tourists. The differences are resulted mainly because are reported in two areas that present different level of tourist development and on which different policies have been applied in the past.

Taking into consideration the hotels potential, it is realised that the searched areas present a different type of tourist development. The area of Faliraki is characterized from a big and intermediate size of hotels units that are scattered in all the coastal extent of Faliraki and less from the rented rooms and the residences.

On the contrary, the area of Delta firstly is characterized from small number and intermediate size hotels units and the rented rooms that are concentrated in Stomio and secondly, from the rented rooms and the seasonal residence of Aiganis.

Also, the research shows that the regions present important difference as to their number of hotels lodgings, to their number of nightly centres, to their restaurants as well as to their commercial shops, where the area of Faliraki exceeds considerably against the Delta of Penaeus. Its main characteristic is that in Faliraki the commercial shops, as well as the centres of recreation and the restaurants are concentrated in the central road of settlement, while in the area of Delta the small number of restaurants and commercial shops are concentrated in the coastal road of Stomio and Aeganis.

Even if the both areas present generally lack of services and dependence on the big neighbouring centres, the Faliraki from Rhodes and the region of Delta from the city of Larissa, the area of Faliraki allocates a high quality infrastructures and services from the big hotels units and intermediate/low quality from the smallest. While, the area of Delta Penaeus allocates only intermediate/low quality tourist lodgings. Thus, the area of Faliraki presents a better organisation and others a high quality services on the tourist sector, in contrary to the area of Delta Penaeus ${ }^{[1]}$.

\section{Problems and land uses regulation:}

Problems: The both coastal areas that research was made, presented insufficient regulation of land uses, with result the appearance of many but different landplanning, urban and environmental problems.

Many problems that are in one area do non exist in the other. For example, in the area of Delta Penaeus is absent the circulatory, the annoying activities, due to many nightly centres, the big hotels groups and the multiple land uses that are observed in the area of Faliraki.

The arbitrary construction: The arbitrary construction and in both areas was strengthened, firstly, by the wish of residents of area for second residence and secondly, by the lack of drawings, from the beginning, for the regulation of land uses. Even the drawings that were made afterwards, when the areas had already been developed finally, they were not applied. In the area of Faliraki the arbitrary construction is reported in all his extent contrary to the area of Delta Penaeus where the arbitrary construction is reported in the areas of Aiganis and Strintzo. The arbitrary seasonal residence presented in the decade of 70 in the areas Loutro-Kastri and Mesangala in the Municipal boreaught of Aiganis, which then it became more systematic in decade of 80 , with extension up to the beach of Koulouras ${ }^{[8]}$. The arbitrary construction was recognized as settlement of new Mesangala. The construction was encouraged by the lack of drawings of land uses and afterwards the determination of Zone of Built-up Control $(\mathrm{ZBC})^{[9]}$, the area was financed for infrastructure constructions works in this. 
The degradation of natural resources: Both regions are not a rational aquatic resources management. This had as result firstly the degradation of this natural resource because of the overpumping of water horizon for agricultural and tourist aims, secondly, the water pollution from the sewages of settlements and tourist lodgings that do not allocate biological cleaning units and thirdly from the restriction of streams or even their destruction (transformation in plots) as it has happened in the area of Aiganis. Also, the forestal had proportional management resources. The forestal areas in the area of Delta suffered bigger degradation and restriction concerning the area of Faliraki ${ }^{[1]}$.

The Degradation of landscape: The aesthetics of landscape was downgraded by the big hotels units and the big dissemination of tourist lodgings in all the area of Faliraki in contrast to the area of Delta that the hotels units are smaller and concentrated in the settlements.

Land uses regulations: Land uses regulation in small extent: The existing drawings of land uses regulations cover a small extent of area. In the area of Delta Penaeus the Zone of Built-up Control (ZBC) is reported only in the area of Aiganis, while the remainder area does not undergo in any management arrangement and protection, for all the natural ecosystems that it allocates. From one hand, the zone tries to regulate the land uses in the area and to protect the unique biotopes of River Penaeus that have remained. On the other hand it strengthens the construction for seasonal residence in area where they were biotopes in the past. The result was to increase the construction, to a large extent, in the next years, destroying, firstly, an important part of streams and, secondly, changing a percentage of rural part in settlement. Similarly, in the area of Faliraki, the existence of General Building Plan (GBP) ${ }^{[10]}$ and ZBC in 1994, did not success to regulate the land uses. Also, it was realised that the areas that were proposed for land uses regulations did not cover all the area, leaving except control her northern part that is characterized today by the appearance of many big hotels units. Thus, from one hand it tries to limit the construction and on the other hand to encourage to other part.

Non approval and non application of land-planning drawings: In the area of Delta Penaeus, the fact that was not finally approved the study of Hellenic Public Real Estate Corporation (HPREC) that aimed the integration of area of Delta Penaeus in the protected areas, had as result to the natural environment, as well as, to the agricultural extents. This happened in the area of Faliraki. Before, it was developed to increase the construction, even if the area had a cadastre and tourist study for land uses regulations, finally these were not applied resulting to the areas' random developed.
Policies that have played important role in the development of both areas: In the in the area of Faliraki the policy of motives for the tourism development played an important role, contrary to the rural policy that was applied in the Delta of Penaeus during the decade of 30 that had as a result the transformation of big forestal area in rural area.

Thus, the area was strengthened more for tourist development, in contrast to the area of Delta that was strengthened more for rural development.

With regard to the development and the protection of environment, important role played the attitude of residents of area. Concretely, in the area of Delta Penaeus the residents not only did not accept the study of HPREC, but also the local institution was financed the study for further tourist development of area. The study had as objective the declassification of the area as protected and its transformation in area of tourist interest.

The research showed that finally the area is developed according to the opinion of residents and no as they would determine by any chance drawings. Of course, the local authorities have the potential of selecting a certain local company for the land uses regulations, so that the residents can make changes in proposed land uses more easily. For example, the Municipality of Down Olympus selected a local company for the elaboration (Drawing for Spatial Built up Organization Open City) (DSBOOC), so that the residents can intervene to the land uses regulation.

However, it is obvious that the residents of the area decide for the determination of land uses and their limits and not the responsible company. The land uses drawings have a direct application and concretization only when they satisfy the ambitions of residents. However, they will try to modify or reject them. For all the above reasons, the studies of HPREC on the protection of Delta Penaeus was not approved as well as the study of Doxiadis ${ }^{[11]}$ due to the land uses regulations that were opposite, to a small extent, with the development drawings of activities of the residents.

The person who is in charge for the work in the area of down Olympus in the area of Mesangala, that is a poor area, claims that the residents want regulating drawings for the transformation of rural area in plots, in order to build or even sell, as their value will be increased.

According to the both land-planning drawings of corresponding areas ${ }^{[12,13]}$, there is a pointing out regarding the already intense pressures of human activities and the degradation of natural resources. At the same time they propose measures for the aid of productions' sectors as well as for the protection of environment. 
The land-planning frames propose the aid of rural sector (protection of agricultural land of high productivity with the support of local special cultures) but also the aid of alternative forms of culture (such as bio-cultural, orientation to qualitative products and projection and promotion of local products in the regional and local market). Moreover, in the area of Delta it is proposed traditional piscicultures development of piscicultures, as well as, shellfish farmings-piscicultures in suitable marine zones, without land installations, with service by the piscatorial shelter of Stomio.

With regard to the secondary sector, it is point out the aid of sector of rural products alteration (modernisation and competitiveness) and also the craftbased units in the area of Faliraki.

In the tertiary sector and in both areas is proposed the development of alternative forms with different objectives in order to elongate the tourist period and the territorial tourism development in the area of Delta Penaeus, contrary to the progressive change of development model of mass tourism in the area of Faliraki. Also, it is proposed the modernization of existing infrastructures and the improvement of provided services.

The land-planning drawings are differentiated as for the degree of tourist development. For the area of Delta it is proposed exploitation of existing reserve for further tourist development. On the contrary, for the area of Faliraki restriction of foundation of new hotels infrastructures and increase of beds are proposed. Also, it is recommended the aid of degree of coveringadditionally between the seasonal and tourist activity, in order to increase the use of the building, as regard the intensity and the allocation of the tourist period.

For the protection of natural resources, the landplanning frames point out the need for land uses regulations, the restriction of construction and the control of tourist development. While, the cultural heritage (monuments, historical places), it should be elected and protected.

Particularly for the area of Delta Penaeus, the landplanning drawing is reported in the characterization of area as "environmental sensitive area", in the syntax of Forestal Cadastre, in the construction of biological cleaning and in the increase of water resource with the deviation of waters of Acheloos to the Thessaly, where it will enrich the water balance. On the contrary, in the area of Faliraki the land-planning drawing is not reported in more, due to it have a cadastre, a third degree biological cleaning and a part of area it has been characterized as protected (Forestal area of prophet Elia).

\section{CONCLUSION}

Both areas present different intensities of land uses and different problems, firstly, due to the different way of development of area and secondly, to the different character of area. Also, the various policies played an important role that were applied in past as well as the active attendance and attitude of authorities as the residents of area.

It is clear that the residents select the way of development of area in bigger degree than the state via the proposed drawings and the economic aid for tourist development.

In both areas, the intensities of land uses had as result the degradation and the restriction of natural resources. The bigger degradation in the area of Faliraki has caused by the building activity due to the tourist development, while in the area of Delta the agricultural activities, with the exception of the area of Aiganis where the degradation was caused by the development of seasonal residence.

Today, in the area of Faliraki with the extension of hotels units, as well as in the area of Delta Penaeus with the extension of seasonal residence, the built-up development is continued with a small rate and threatens the natural resources of both areas.

By all the above concluded that, the intensity of land uses in the coastal areas causes the bigger degradation of natural resources. The active attendance is necessary not only from the local authorities but also from the residents of area in order to decrease the environmental repercussions through the application of various land-planning drawings that are proposed by the state for the land uses regulations. In addition to this, the social conjunction and the briefing are necessary condition for the success of any plan and program.

\section{REFERENCES}

1. Economou, A., 2007. The contribution of regional planning to the confrontation of environmental problems in the Greek coastal area and the European policy. National Technical University Athens (NTUA), Dissertations, Athens, pp: 13, 279-286.

2. Economou, A., 2007. Tourist development in the coastal natural environment of Faliraki on the island of Rhodes. Proceedings of 12th International Conference on Urban Planning and Spatial Development in the Information Society, May 2023, Wien, Austria, pp: 703-712. http://programm.corp.at/proceedings/CORP2007_p roceedings.pdf 
3. Economou, A., 2005. The coastal zone of the pinios river delta: Development and protection of the environment. Techn. Chron. Sci. J. TCG, 25: 37-46. http://portal.tee.gr/portal/page/portal/PUBLICATI ONS/SCIENTIFIC_PUBLICATIONS/SEIRA_II/2 005/03-OIKONOMOU.pdf

4. National Statistical Service of Greece, 2001. Statistical data: employment cencus of productivities' sectors.

5. National Statistical Service of Greece, 2001. Statistical data: housin cencus.

6. National Statistical Service of Greece, 2004. Statistical data: tourist movement in Greece.

7. Greek Organism of Tourism, Administration of Tourism of Dodecaneusus, 2000. Tourist movement of Prefecture of Dodecaneusus for year 2000, Rhodes, pp: 15-16.

8. Voivonda A. and Gkionis G., 2001. Study of improvement and exploitation of regions of the Estuaries of Penaeus River, Hellenic Public Real Estate Corporation (HPREC), Athens, pp: 1-54.
9. Official Journal of the Hellenic Republic, 589 D'/22.10.1990., pp: 5393-5400 http://www.et.gr/search_publication

10. Official Journal of the Hellenic Republic, 721 D'/19.07.1994, pp: 7077-7104 http://www.et.gr/search_publication

11. Doxiadis Company, Study of Tourist development of Faliraki of Rhodes, DA, DOX-GRE-A-254, Athens, 1969, pp: 1-85.

12. Official Journal of the Hellenic Republic, 1484 B'/10.10.2003, pp: 20749-20780 http://www.et.gr/search_publication

13. Official Journal of the Hellenic Republic, 1487 B $^{\prime} / 10.10 .2003$, pp: 20857-20888

http://www.et.gr/search_publication 